The Longitudinal Association Between Poor Sleep Quality And Cyberbullying, Mediated by Anger

Sara Erreygers ${ }^{1,2}$, Heidi Vandebosch ${ }^{1}$, Ivana Vranjes ${ }^{1,2,3}$, Elfi Baillien ${ }^{3}$, \& Hans De Witte E $^{2,4}$

${ }^{1}$ Department of Communication Studies, Faculty of Social Sciences, University of Antwerp, Belgium; ${ }^{2}$ Occupational \& Organisational Psychology and Professional Learning, KU Leuven, Leuven, Belgium; ${ }^{3}$ Department of Work and Organization Studies, KU Leuven, Brussels, Belgium; ${ }^{4}$ Optentia Research Focus Area, Vanderbijlpark Campus, North-West University, South-Africa.

Author Note

This research was supported by the Research Foundation Flanders, grant number FWO G.0335.14N.

Correspondence and reprint requests concerning this article should be addressed to Sara Erreygers, Department of Communication Studies, University of Antwerp, S.Z. 109, SintJacobsstraat 2-4, 2000 Antwerpen, Belgium. E-mail: sara.erreygers @ uantwerpen.be. Phone: +32 32655036. 


\begin{abstract}
Adolescents tend to go to bed later and sleep less as they grow older, although their need for sleep stays the same throughout adolescence. Poor sleep has negative consequences on personal and interpersonal functioning, including increased aggressive tendencies. With adolescents' social life increasingly including interactions via digital media, these interactions may also become more aggressive when adolescents' sleep problems increase. One of the ways in which online aggression may be enacted, is through cyberbullying. Although previous research has examined the role of sleep disruptions in offline bullying, the role of sleep in cyberbullying has not yet been addressed. Therefore, this study examines the longitudinal effect of poor sleep quality on later cyberbullying behavior. 13-14 year old adolescents completed selfreport measures on sleep quality, anger, cyberbullying perpetration, and frequency of digital media use. Because one of the pathways through which sleep is proposed to be linked to aggression is an affective pathway, namely via angry affect, a mediation model of poor sleep quality predicting cyberbullying via feelings of anger was tested. Results from structural equations modeling and a bootstrap test indicated that poor sleep quality was indeed indirectly associated with later cyberbullying behavior through heightened feelings of anger, even when taking the effects of use of digital media and previous cyberbullying behavior into account. This finding provides support for the proposed affective pathway linking sleep problems to aggression. As sleep problems and anger seem to play a predicting role in cyberbullying behavior, suggestions for cyberbullying intervention and prevention strategies are formulated.
\end{abstract}




\section{The Longitudinal Association Between Poor Sleep Quality And Cyberbullying, Mediated}

\section{by Anger}

The negative consequences of poor sleep on personal and interpersonal functioning have extensively been documented in adults as well as in children and adolescents (Harvey, Murray, Chandler, \& Soehner, 2011; Roth \& Roehrs, 2003; Shochat, Cohen-Zion, \& Tzischinsky, 2014). One of the interpersonal functioning domains affected by sleep disruptions is aggression: Crossdisciplinary research has shown a clear link between sleep problems and aggression (Kamphuis, Meerlo, Koolhaas, \& Lancel, 2012; Krizan \& Herlache, 2016).

In a review integrating cross-disciplinary evidence of the effects of sleep disturbance on aggression, Krizan and Herlache (2016) suggest that sleep problems may play an important role in the domain of offline bullying and cyberbullying (i.e., intentional negative behavior that occurs through the use of electronic technologies; Smith et al., 2008). Insufficient sleep predicts decreased neurobehavioral functioning, impeding crucial behavioral and mental functions needed for adequate social interaction (Gregory \& Sadeh, 2012; Krizan \& Herlache, 2016). Over time sleep disruptions may thus contribute to aggressive behavior and bullying among students, which can be evident at school and online (Krizan \& Herlache, 2016). In this domain, sleep-targeted interventions at the individual and/or institutional level may be promising avenues for intervention and prevention of children and adolescents' antisocial interpersonal behavior.

Previous studies have indicated that sleeping problems in children and adolescents are related to offline bullying and aggression. For instance, in a study with 49 healthy 7 - to 12 -year old children, objectively measured (with belt-worn activity monitors) low sleep time was associated with teacher-reported externalizing symptoms such as aggressive and delinquent behavior (Aronen, Paavonen, Fjällberg, Soininen, \& Törrönen, 2000). Further, a survey study 
among parents of 2- to 14-year old children visiting two general clinics showed that parent-rated bullying and other aggressive behaviors were associated with symptoms of sleep disorders (sleep-disordered breathing, restless legs syndrome, or periodic leg movements during sleep; Chervin, Dillon, Archbold, \& Ruzicka, 2003). Findings from a study among 5,420 Scottish secondary school pupils indicated that victims, bullies, and bully-victims were more likely to experience sleep difficulties when compared to uninvolved pupils (Hunter, Durkin, Boyle, Booth, \& Rasmussen, 2014). However, to date no studies have examined the role of sleep in cyberbullying among adolescents, which might be especially relevant, because (1) adolescents intensively use digital platforms to communicate with their peers (Lenhart, Smith, Anderson, Duggan, \& Perrin, 2015), (2) high use of digital media negatively affects adolescents' sleep (Cain \& Gradisar, 2010), and (3) sleep loss impedes social interactions with peers (Sarchiapone et al., 2014). Therefore, the aim of this study is to investigate the potential relevance of sleep in explaining cyberbullying perpetration behavior, and the possible mediating path via anger.

\section{Adolescent Sleep and Cyberbullying Characteristics}

Sleep as well as cyberbullying are particularly relevant during adolescence. As adolescents grow older, they go to bed increasingly later (Crowley, Acebo, \& Carskadon, 2007). However, their schools require them to rise early and this combined with their delayed bedtime diminishes their sleep time, especially during weekdays. Yet, the hours of sleep that adolescents need is the same from age 10 to 17 . Poor sleep quality and quantity are therefore common in adolescence (Moran \& Everhart, 2012).

Adolescence is also a pertinent life phase regarding cyberbullying. Cyberbullying occurs from childhood to adulthood, but it shows a clear peak during early adolescence (for a metaanalytical review, see Kowalski, Giumetti, Schroeder, \& Lattanner, 2014). Cyberbullying is 
related to a host of negative short- and long-term consequences (Zych, Ortega-Ruiz, \& Del Rey, 2015), therefore it is highly important to gain more insight into its antecedents to advance the development of effective prevention strategies.

Both sleep and cyberbullying are related to the use of digital media. Youngsters are particularly avid users of digital media: In 2014 the highest daily use of the internet in EUcountries was among 16-19 year olds (Eurostat, 2015). As cyberbullying is intentional negative behavior that occurs through the use of electronic technologies (Smith et al., 2008), this behavior can only occur if people use digital media. Moreover, research suggests that a higher use of digital media is associated with increased cyberbullying (e.g., Walrave \& Heirman, 2011).

Digital media use also has an adverse effect on sleep: More frequent use of digital media leads to later bed times, less sleep hours, and more tiredness (for a review, see Cain \& Gradisar, 2010). For instance, in a study with 2,546 adolescents, television viewing, computer game playing, and internet use were all related to sleep disturbances (Van den Bulck, 2004).

\section{Sleep and Aggression}

Research findings from several disciplines corroborate the clinical observation that sleep problems can fuel aggressive behavior (for reviews, see Kamphuis et al., 2012; Krizan \& Herlache, 2016). This link between sleep loss and amplified aggressive reactions is likely mediated by the detrimental effect of sleep disruptions on neurobiological systems such as prefrontal cortical functioning, serotonin, and the hypothalamic-pituitary-adrenal-axis (Kamphuis et al., 2012). The impairment of these systems may contribute to the loss of affective, cognitive, and response-control functions related to aggressive responses (Krizan \& Herlache, 2016), in accordance with the General Aggression Model (GAM; Anderson \& Bushman, 2002). The GAM provides an overarching, comprehensive social-cognitive framework of aggression. It 
proposes three main stages in situations of aggression: person and situation inputs, routes (internal states, namely cognitive, physiological, and affective pathways), and outcomes of appraisal and decision processes (Anderson \& Bushman, 2002). In this study, the focus is on the affective pathway linking sleep problems to aggression, in particular cyberbullying.

Bullying is a particular form of aggression with three specific characteristics: repeated behavior, intention to harm, and power imbalance (Olweus, 1996). Especially in the online context, it can be difficult to tease bullying and aggression apart, as not all criteria to distinguish offline bullying from aggression may be necessary to define cyberbullying (in particular repetition and power imbalance; Thomas, Connor, \& Scott, 2015). Models and theories from the aggression literature (e.g., the GAM) are often applied to (cyber)bullying (Kowalski et al., 2014), and aggressive motivations seem to underlie cyberbullying acts (Law, Shapka, Domene, \& Gagné, 2012). Therefore, both research on the role of sleep in aggression and in bullying are relevant when examining the role of sleep in cyberbullying.

The Role of Anger. One way through which sleep problems may lead to aggressive responses is via an affective pathway, specifically through anger (Kamphuis \& Lancel, 2015; Krizan \& Herlache, 2016). Anger is a strong negative emotion felt in response to a perceived wrongdoing (Averill, 1983). People experience anger in situations that they appraise as unfair and unpleasant and in which one's goals are obstructed (Scherer, 1997). Here, the terms 'anger', 'angry affect' and 'angriness' are used interchangeably to refer to the subjective experience of feeling angry, encompassing more long-lasting and diffuse moods as well as more specific, situation-bound emotions (Gross \& Thompson, 2007). Multiple - mostly correlational and selfreport - studies have shown that sleep disruptions (in terms of decreased sleep duration or 
diminished sleep quality) are associated with increased anger and hostility (e.g., Lund, Reider, Whiting, \& Prichard, 2010; Shin et al., 2005).

The path from anger to aggression has also received much research attention. Anderson and Bushman (2002) argue that anger elicits aggressive tendencies and these tendencies are not only directed towards the anger instigator, but also often to non-related individuals (i.e., displaced aggression; Fenigstein \& Buss, 1974). This is especially relevant in cyberbullying, as the internet provides an unlimited number of possible targets to aggress against. Moreover, anger that cannot be expressed offline (for example, because of fear of being hurt physically or because of a power difference), can often be acted out more easily online, where individuals can remain anonymous, harass others 24/7, and escape (adult) supervision (cf., the online disinhibition effect; Suler, 2004). Several studies have provided support for an association between anger and cyberbullying (Ak, Özdemir, \& Kuzucu, 2015; den Hamer, Konijn, \& Keijer, 2014; Lonigro et al., 2015).

\section{This Study}

Taken together, the reviewed research suggests that sleep disturbances may lead to cyberbullying through increased feelings of anger. This process is particularly relevant in adolescence, when individuals are especially prone to sleep problems and cyberbullying involvement, combined with and reinforced by high use of digital media. Therefore, this study examines whether sleep problems predict later cyberbullying behavior through angriness among adolescents. Although sleep has many dimensions, such as sleep quality, sleep duration, and drowsiness, which may all affect aggression, the current study focuses on one aspect of sleep, namely the effect of poor sleep quality, on adolescents' cyberbullying behavior. Using longitudinal data from a large sample of Belgian adolescents, the study tests a mediation model 
of sleep quality and cyberbullying perpetration via anger, taking into account adolescents' previous involvement in cyberbullying. Frequency of digital media use was also controlled for at both time points. This variable correlates with both the independent (sleep quality) and dependent (cyberbullying perpetration) variable. Therefore, it could be a confounder resulting in a possible spurious association between these two variables if not controlled for. The conceptual model is illustrated in Figure 1.

[Figure 1 about here]

\section{Method}

\section{Procedure}

This study was part of a three-wave longitudinal research project. For this study, data from the second (T1: October-November 2015) and third wave (T2: March-May 2016) were used, because sleep quality was not measured in the first wave. The participants completed the survey on paper or electronically during school hours in the presence of the first author and/or thoroughly informed school staff. They were ensured that their answers would be treated confidentially and anonymously. To be able to link the participants' surveys across the waves, they were asked to provide the first letter of their own and their parents' first name, their gender and their date of birth. The study received ethical approval from the Ethics Committee for the Social Sciences and Humanities of the University of Antwerp, Belgium.

\section{Participants}

The participants were pupils from the second year of secondary education (equivalent to US grade 8). They were recruited via schools, which were randomly selected from the pool of all secondary schools in the province of Antwerp, Belgium. Of the 30 schools that were contacted, 13 schools agreed to participate; the other refused out of practical reasons, because they did not 
want to lose valuable class time to the administration of a survey, or because they were not able to comply with all research participation requests they had received. The participating schools were representative in terms of type of schooling offered (general education or vocational education). After the school principals provided active informed consent, all students from the second year were eligible for participation and their parents received a passive informed consent form. Thirteen pupils opted out of participation, resulting in a sample of 1,746 adolescents (45.1\% boys) at $\mathrm{T} 1$, and 1,590 (44.3\% boys) at $\mathrm{T} 2$. Two entire classes at $\mathrm{T} 1$ and eight classes at T2 did not participate due to practical issues during data collection. Participants were on average 13.55 years old $(S D=0.55)$ at $\mathrm{T} 1$ and 14.08 years old $(S D=0.56)$ at $\mathrm{T} 2$.

\section{Measures}

Sleep quality. The revised Adolescent Sleep-Wake Scale (Essner, Noel, Myrvik, \& Palermo, 2015), a shortened version of the Adolescent Sleep-Wake Scale (ASWS; LeBourgeois, Giannotti, Cortesi, Wolfson, \& Harsh, 2005) assessed participants' sleep quality. This 10-item scale comprises three subscales: Falling Asleep and Reinitiating Sleep (FARS), Returning to Wakefulness (RTW), and Going to Bed (GTB), measured on a 6-point Likert-type scale ranging from 1 (never) to 6 (always), with higher scores indicating better sleep quality. A second-order confirmatory factor analysis (CFA) was performed with the three subscales as first-order factors and Sleep Quality (SQ) as second-order factor, as the subscales were not the focus of this study. One item of the FARS-subscale ("When it's time to go to sleep, I have trouble settling down" reverse coded) was omitted because it had a low factor loading and modification indices indicated that it cross-loaded on the other subscales. The second-order CFA had an acceptable fit, $\mathrm{RMSEA}=.066(90 \% \mathrm{CI}[.058, .074]), \mathrm{CFI}=.942, \mathrm{TLI}=.916, \mathrm{SRMR}=.046$, and Cronbach's alpha was .728. 
Anger. Adolescents were asked how often they felt angry in the past month. They rated their experience on a 7-point Likert-type scale ranging from 1 (never) to 7 ([almost] all the time).

Cyberbullying perpetration. Adolescents' perpetration of cyberbullying was assessed with the 11 items from the European Cyberbullying Intervention Project Questionnaire (Brighi et al., 2012; Del Rey et al., 2015; Schultze-Krumbholz et al., 2014). Participants had to rate how often in the past month they had performed each of the 11 behaviors via digital media (e.g., "Say mean things to someone or call someone names") on a 5-point Likert-type scale ranging from 1 (never) to 5 (every day). One item ("Post embarrassing videos or pictures of others online") was excluded from the analysis because participants remarked that they do this for fun on Facebook for friends' birthdays. As the rating scale had only five categories and the response distributions were skewed, weighted least squares with mean and variance adjustment (WLSMV) estimation was used in the analysis (Rhemtulla, Brosseau-Liard, \& Savalei, 2012). A CFA with all items loading on one factor yielded an acceptable fit for time 1, RMSEA = .074 (90\% CI [.067, .081]), $\mathrm{CFI}=.907, \mathrm{TLI}=.881$, and time $2, \mathrm{RMSEA}=.084(90 \% \mathrm{CI}[.077, .091]), \mathrm{CFI}=.942, \mathrm{TLI}$ $=.925$. Cronbach's alphas were .756 for time 1 and .788 for time 2 .

Frequency of digital media use. The items used in the Belgian version of the EU Kids Online questionnaire (EU Kids Online, 2014) assessed participants' frequency of digital media use in the past six months. On a 6-point scale ranging from 1 (never) to 6 (multiple times per day), participants indicated how often they had performed each of 17 activities via digital media (e.g., "Visited a social network site"). Two items were deleted because they referred to activities that most participants did not understand ("Using a chatroom", "Using data sharing websites"). For the purpose of this study, only the aggregated effect of all the activities together was of 
interest (i.e., the quantity of use of digital media rather than the quality or different types);

therefore the items were treated as composite indicators and a composite variable of frequency of digital media use was constructed as the mean of the 15 remaining items. Cronbach's alpha for this scale was .796 at $\mathrm{T} 1$ and .795 at $\mathrm{T} 2$.

\section{Analysis}

A mediation model was constructed using Mplus 7.4 (Muthén \& Muthén, 2015).

Cyberbullying perpetration at $\mathrm{T} 2$ was predicted by sleep quality at $\mathrm{T} 1$, with mediation via anger at T2. Anger at T2 was chosen because the effects of anger on aggression seem to happen on short term (however, we also tested a model with anger assessed at T1, cf., infra). To account for the effect of previous cyberbullying perpetration behavior, T1 cyberbullying perpetration was controlled for by predicting T2 cyberbullying perpetration. In so doing, the effect of sleep and anger on change in cyberbullying behavior from T1 to T2 is assessed. Also, as both cyberbullying and decreased sleep quality have been associated with use of digital media, this variable was controlled for as well through regressing T1 sleep quality on T1 frequency of digital media use and T2 cyberbullying perpetration on T2 frequency of digital media use.

Some of the variables were ordered categorical in nature, therefore the WLSMVestimator was used (Rhemtulla et al., 2012). Missing data were MCAR and were handled using pairwise deletion, which is the default in Mplus, resulting in a sample size of 1,386 adolescents with complete data. The indirect effect was tested via a bootstrap analysis with 1,000 samples, generating a $95 \%$ confidence interval of the indirect effect, which indicates a significant effect when the interval does not include 0 .

\section{Results}

[Table 1 about here] 
First, descriptive statistics of the study variables (all as composites) were calculated with SPSS (see Table 1). Then, structural equations modeling was performed with Mplus 7.4 (Muthén \& Muthén, 2015) to test the proposed mediation model. Anger and frequency of digital media use were entered as manifest variables, whereas sleep quality (second order factor) and cyberbullying perpetration were latent variables. In a preliminary analysis, a model without mediation by anger was constructed: T2 cyberbullying perpetration was predicted by $\mathrm{T} 1$ sleep quality directly, while controlling for T1 cyberbullying perpetration and frequency of digital media use. This model had an acceptable to good fit: RMSEA $=.034$ (90\% CI [.032, .036]), CFI $=.932, \mathrm{TLI}=.926$. The parameter estimates suggested a significant direct association between T1 sleep quality and T2 cyberbullying perpetration $(\beta=-0.112, p=.012)$. The associations between T1 and T2 cyberbullying perpetration $(\beta=0.580, p<.001)$, T1 sleep quality and T1 frequency of digital media use $(\beta=-0.561, p<.001)$, and T2 cyberbullying perpetration and T2 frequency of digital media use $(\beta=0.108, p=.002)$ were also significant.

Next, a mediation model was constructed whereby $\mathrm{T} 2$ cyberbullying perpetration was predicted by T1 sleep quality, mediated via T2 anger (see Figure 2). T1 cyberbullying perpetration and frequency of digital media use were entered as control variables. This model also had an acceptable to good fit: RMSEA $=.035(90 \%$ CI $[.033, .037])$, CFI $=.925$, TLI $=.918$. There appeared to be a small but significant indirect effect of sleep quality on later cyberbullying perpetration via anger: $\beta=-0.061, p<.001$. Results of the bootstrap analysis confirmed this, as indicated by the $95 \%$ CI [-0.099, -0.029] which does not include zero. Together, these results suggested indirect-only mediation (Zhao, Lynch Jr., \& Chen, 2010) of decreased sleep quality on cyberbullying perpetration via increased feelings of anger. 
As a check of the robustness of our results, we also tested a model with anger at T1 as mediating variable. This model demonstrated a good fit as well, RMSEA $=.035(90 \% \mathrm{CI}$ $[.033, .037]), \mathrm{CFI}=.923, \mathrm{TLI}=.916$, and the results of the parameter estimates were similar. $\mathrm{A}$ cross-sectional model with all variables measured at T2 (but still controlling for cyberbullying perpetration at T1) also had a comparable fit, RMSEA $=.035(90 \%$ CI $[.033, .037]), \mathrm{CFI}=.922$, $\mathrm{TLI}=.915$, and similar results for the parameter estimates. Detailed results of these models can be obtained by request from the first author.

[Figure 2 about here]

\section{Discussion}

Research increasingly suggests that sleep problems promote aggression (Kamphuis et al., 2012; Krizan \& Herlache, 2016). One of the proposed paths through which disruptions in sleep may fuel aggressive tendencies is an affective path, namely through anger (Kamphuis \& Lancel, 2015). This study aimed to test this process for one form of aggression that is especially relevant in adolescence: cyberbullying. As both poor sleep quality (Cain \& Gradisar, 2010) and engagement in cyberbullying (Walrave \& Heirman, 2011) are associated with the use of digital media, the influence of this variable was also taken into account. Using longitudinal data collected among 13-14 year old adolescents, a mediation model of sleep quality predicting later cyberbullying via anger was tested, with a bootstrap test of the indirect effect.

Our results indicate that, after accounting for previous cyberbullying perpetration and frequency of digital media use, poor sleep quality predicts later cyberbullying perpetration indirectly via increased feelings of anger. This finding provides support for the proposed affective pathway of sleep problems to aggression via anger (Krizan \& Herlache, 2016) and fits within the predictions of the GAM (Anderson \& Bushman, 2002) about how personal variables, 
such as sleep problems, can lead to aggression via an affective path. Moreover, these findings are in accordance with previous studies that have reported associations between disrupted sleep and anger (e.g., Shin et al., 2005), and between anger and aggression or cyberbullying (e.g., Ak et al., 2015).

One of the strengths of this study is the use of longitudinal data, which allowed to analyze temporal processes and to control for previous engagement in cyberbullying in the prediction of cyberbullying perpetration by sleep problems. Moreover, use of digital media was also controlled for, as this variable is associated with both sleep disruptions (Cain \& Gradisar, 2010) and cyberbullying (Walrave \& Heirman, 2011).

Notwithstanding these strengths, some limitations need to be addressed. As not all the schools that were contacted agreed to participate, there may have been a selection bias in the study sample, such that those schools that were more concerned with their students' well-being may have been more likely to participate. Although this could influence the means of the variables, it seems unlikely that this would have an effect on the reported associations. Furthermore, although the study sample was large, the age range was narrow. Generalizations of these findings to considerably younger or older populations may not be warranted. It would be interesting to test whether the process found here (from sleep problems to cyberbullying perpetration via anger) also holds in other populations, or whether other or additional processes (such as mediation via the cognitive path) play a more important role. Another important limitation regards the measures used in this study. Anger in the past month was assessed with a one-item measure. The use of a multi-item measure of anger could be advised for future studies. Furthermore, the assessed time period of one month is rather long. Although we tried to facilitate recall by assessing adolescents' experienced events in the past months prior to assessing their 
emotions, it may still have been difficult to report their level of angriness over the period of the past month. Also, the interval between the two measurement occasions was six months, which is a long time to assess the effect of emotions, as emotions are short-lived and immediate reactions to changes in the environment. However, poor sleep quality is often chronic in adolescence and may develop (increase or decrease) over the course of a longer timeframe (Fredriksen, Rhodes, Reddy, \& Way, 2004). This created issues for the design of the study regarding the optimal time point to assess each variable. In our model, we decided to assess anger and cyberbullying at the same time, but an equivalent model with anger assessed at the previous time point (i.e., together with the measurement of sleep quality) and a model with all variables assessed cross-sectionally at T2 (while still controlling for previous cyberbullying perpetration) yielded comparable results.

The findings of this study entail some important implications. As our results suggest that sleeping problems fuel cyberbullying perpetration behavior through heightened anger, several suggestions can be formulated for practitioners. Firstly, intervention and prevention strategies against cyberbullying could benefit from addressing adolescents' sleep patterns. Several measures can be taken to improve adolescents' sleep, at the individual as well as at the institutional level, such as promoting sleep hygiene (Moran \& Everhart, 2012). Secondly, the regulation of anger could also be addressed. By teaching adolescents how to regulate their anger (and other emotions), they may feel less inclined to act out their anger towards other people online. Programs targeting emotion regulation in adolescents, such as the mindfulness-based program Learning to BREATHE (Metz et al., 2013), could be helpful in this regard, as could interventions that deter individuals to vent their frustrations online when they are angry. Perhaps angry individuals could also benefit from positive mood management strategies, such as watching funny cat videos, to temper their negative feelings (Myrick, 2015). Additionally, digital 
platforms could make use of reflective interfaces to automatically detect potentially harmful content and encourage users to reflect about what they intend to post before they actually post it (Dinakar, Jones, Havasi, Lieberman, \& Picard, 2012).

In conclusion, the findings from this study suggest that sleep problems predict cyberbullying perpetration in adolescents through heightened feelings of anger, confirming the affective path to aggression as proposed by the General Aggression Model (Anderson \& Bushman, 2002). This study is the first to examine the path from sleep problems to cyberbullying, and we think many other associations between cyberbullying and sleep need to be explored, such as the association between sleep and cyberbullying victimization, possible mutual reinforcing effects of cyberbullying involvement and sleep problems, and many more. We hope this study can serve as an inspiration for more research on the relation between sleep and cyberbullying. 


\section{References}

Ak, Ş., Özdemir, Y., \& Kuzucu, Y. (2015). Cybervictimization and cyberbullying: The mediating role of anger, don't anger me! Computers in Human Behavior, 49, 437-443. doi:10.1016/j.chb.2015.03.030

Anderson, C. A., \& Bushman, B. J. (2002). Human aggression. Annual Review of Psychology, 53, 27-51. doi:10.1146/annurev.psych.53.100901.135231

Aronen, E. T., Paavonen, E. J., Fjällberg, M., Soininen, M., \& Törrönen, J. (2000). Sleep and psychiatric symptoms in school-age children. Journal of the American Academy of Child \& Adolescent Psychiatry, 39, 502-508. doi:10.1097/00004583-200004000-00020

Averill, J. R. (1983). Studies on anger and aggression: Implications for theories of emotion. American Psychologist, 38, 1145-1160.

Brighi, A., Ortega, R., Pyzalski, J., Scheithauer, H., Smith, P. K., Tsormpatzoudis, H., \& Al., E. (2012). European Cyberbullying Intervention Project Questionnaire - ECIPQ.

Cain, N., \& Gradisar, M. (2010). Electronic media use and sleep in school-aged children and adolescents: A review. Sleep Medicine, 11, 735-742. doi:10.1016/j.sleep.2010.02.006

Chervin, R. D., Dillon, J. E., Archbold, K. H., \& Ruzicka, D. L. (2003). Conduct problems and symptoms of sleep disorders in children. Journal of the American Academy of Child \& Adolescent Psychiatry, 42, 201-208. doi:10.1097/00004583-200302000-00014

Crowley, S. J., Acebo, C., \& Carskadon, M. A. (2007). Sleep, circadian rhythms, and delayed phase in adolescence. Sleep Medicine, 8, 602-612. doi:10.1016/j.sleep.2006.12.002

Del Rey, R., Casas, J. A., Ortega-Ruiz, R., Schultze-Krumbholz, A., Scheithauer, H., Smith, P., ... Plichta, P. (2015). Structural validation and cross-cultural robustness of the European Cyberbullying Intervention Project Questionnaire. Computers in Human Behavior, 50, 141- 
147. doi:10.1016/j.chb.2015.03.065

den Hamer, A., Konijn, E. A., \& Keijer, M. G. (2014). Cyberbullying behavior and adolescents' use of media with antisocial content: A cyclic process model. Cyberpsychology, Behavior, and Social Networking, 17, 74-81. doi:10.1089/cyber.2012.0307

Dinakar, K., Jones, B., Havasi, C., Lieberman, H., \& Picard, R. (2012). Common sense reasoning for detection, prevention, and mitigation of cyberbullying. ACM Transactions on Interactive Intelligent Systems, 2(3), 1-30. doi:10.1145/2362394.2362400

Essner, B., Noel, M., Myrvik, M., \& Palermo, T. (2015). Examination of the factor structure of the Adolescent Sleep-Wake Scale (ASWS). Behavioral Sleep Medicine, 13, 296-307. doi:10.1080/15402002.2014.896253

EU Kids Online. (2014). EU Kids Online: findings, methods, recommendations. London, UK. Eurostat. (2015). Being young in Europe today. Luxembourg.

Fenigstein, A., \& Buss, A. H. (1974). Association and affect as determinants of displaced aggression. Journal of Research in Personality, 7, 306-313. doi:10.1016/00926566(74)90052-X

Fredriksen, K., Rhodes, J., Reddy, R., \& Way, N. (2004). Sleepless in Chicago: Tracking the effects of adolescent sleep loss during the middle school years. Child Development, 75, 8495. doi:10.1111/j.1467-8624.2004.00655.x

Gregory, A. M., \& Sadeh, A. (2012). Sleep, emotional and behavioral difficulties in children and adolescents. Sleep Medicine Reviews, 16(2), 129-136. doi:10.1016/j.smrv.2011.03.007

Gross, J. J., \& Thompson, R. A. (2007). Emotion regulation: Conceptual foundations. In J. Gross (Ed.), Handbook of emotion regulation (pp. 3-24). New York: Guilford Press. doi:10.1080/00140130600971135 
Harvey, A. G., Murray, G., Chandler, R. A., \& Soehner, A. (2011). Sleep disturbance as transdiagnostic: Consideration of neurobiological mechanisms. Clinical Psychology Review, 31, 225-235. doi:10.1016/j.cpr.2010.04.003

Hunter, S. C., Durkin, K., Boyle, J. M. E., Booth, J. N., \& Rasmussen, S. (2014). Adolescent bullying and sleep difficulties. Europe's Journal of Psychology, 10, 740-755. doi:10.5964/ejop.v10i4.815

Kamphuis, J., \& Lancel, M. (2015). The interrelations between sleep, anger, and loss of aggression control. In K. Babson \& M. Feldner (Eds.), Sleep and affect: Assessment, theory, and clinical implications (pp. 247-271). Academia Press.

Kamphuis, J., Meerlo, P., Koolhaas, J. M., \& Lancel, M. (2012). Poor sleep as a potential causal factor in aggression and violence. Sleep Medicine, 13, 327-334. doi:10.1016/j.sleep.2011.12.006

Kowalski, R. M., Giumetti, G. W., Schroeder, A. N., \& Lattanner, M. R. (2014). Bullying in the digital age: A critical review and meta-analysis of cyberbullying research among youth. Psychological Bulletin, 140, 1073-1137. doi:10.1037/a0035618

Krizan, Z., \& Herlache, A. D. (2016). Sleep disruption and aggression: Implications for violence and its prevention. Psychology of Violence, 6, 542-552. doi:10.1037/vio0000018

Law, D. M., Shapka, J. D., Domene, J. F., \& Gagné, M. H. (2012). Are cyberbullies really bullies? An investigation of reactive and proactive online aggression. Computers in Human Behavior, 28, 664-672. doi:10.1016/j.chb.2011.11.013

LeBourgeois, M. K., Giannotti, F., Cortesi, F., Wolfson, A. R., \& Harsh, J. (2005). The relationship between reported sleep quality and sleep hygiene in Italian and American adolescents. Pediatrics, 115, 257-265. doi:10.1542/peds.2004-0815H 
Lenhart, A., Smith, A., Anderson, M., Duggan, M., \& Perrin, A. (2015). Teens, technology \& friendships. Pew Research Center.

Lonigro, A., Schneider, B. H., Laghi, F., Baiocco, R., Pallini, S., \& Brunner, T. (2015). Is cyberbullying related to trait or state anger? Child Psychiatry \& Human Development, 46, 445-454. doi:10.1007/s10578-014-0484-0

Lund, H. G., Reider, B. D., Whiting, A. B., \& Prichard, J. R. (2010). Sleep patterns and predictors of disturbed sleep in a large population of college students. Journal of Adolescent Health, 46, 124-132. doi:10.1016/j.jadohealth.2009.06.016

Metz, S. M., Frank, J. L., Reibel, D., Cantrell, T., Sanders, R., \& Broderick, P. C. (2013). The effectiveness of the Learning to BREATHE program on adolescent emotion regulation. Research in Human Development, 10, 252-272. doi:10.1080/15427609.2013.818488

Moran, A. M., \& Everhart, D. E. (2012). Adolescent sleep: Review of characteristics, consequences, and intervention. Journal of Sleep Disorders: Treatment \& Care, 1(2), 1-8.

Muthén, L. K., \& Muthén, B. O. (2015). Mplus user's guide. Seventh edition. Los Angeles, CA: Muthén \& Muthén.

Myrick, J. G. (2015). Emotion regulation, procrastination, and watching cat videos online: Who watches Internet cats, why, and to what effect? Computers in Human Behavior, 52, 168176. doi:10.1016/j.chb.2015.06.001

Olweus, D. (1996). Gewalt in der Schule: Was Lehrer und Eltern wissen sollten - und tun können [Violence in school: What teachers and parents should know - And can do]. Bern: Huber.

Rhemtulla, M., Brosseau-Liard, P. É., \& Savalei, V. (2012). When can categorical variables be treated as continuous? A comparison of robust continuous and categorical SEM estimation 
methods under suboptimal conditions. Psychological Methods, 17, 354-373. doi:10.1037/a0029315

Roth, T., \& Roehrs, T. (2003). Insomnia: Epidemiology, characteristics, and consequences. Clinical Cornerstone, 5(3), 5-15. doi:10.1016/S1098-3597(03)90031-7

Sarchiapone, M., Mandelli, L., Carli, V., Iosue, M., Wasserman, C., Hadlaczky, G., ... Wasserman, D. (2014). Hours of sleep in adolescents and its association with anxiety, emotional concerns, and suicidal ideation. Sleep Medicine, 15, 248-254. doi:10.1016/j.sleep.2013.11.780

Scherer, K. R. (1997). The role of culture in emotion-antecedent appraisal. Journal of Personality and Social Psychology, 73, 902-922.

Schultze-Krumbholz, A., Göbel, K., Scheithauer, H., Brighi, A., Guarini, A., Tsorbatzoudis, H., ... Smith, P. K. (2015). A comparison of classification approaches for cyberbullying and traditional bullying using data from six European countries. Journal of School Violence, 14, 47-65. doi:10.1080/15388220.2014.961067

Shin, C., Kim, J., Yi, H., Lee, H., Lee, J., \& Shin, K. (2005). Relationship between trait-anger and sleep disturbances in middle-aged men and women. Journal of Psychosomatic Research, 58, 183-189. doi:10.1016/j.jpsychores.2004.07.002

Shochat, T., Cohen-Zion, M., \& Tzischinsky, O. (2014). Functional consequences of inadequate sleep in adolescents: A systematic review. Sleep Medicine Reviews, 18, 75-87. doi:10.1016/j.smrv.2013.03.005

Smith, P. K., Mahdavi, J., Carvalho, M., Fisher, S., Russell, S., \& Tippett, N. (2008). Cyberbullying: Its nature and impact in secondary school pupils. Journal of Child Psychology and Psychiatry and Allied Disciplines, 49, 376-385. doi:10.1111/j.1469- 
7610.2007.01846.x

Suler, J. (2004). The online disinhibition effect. CyberPsychology \& Behavior, 7, 321-326. doi:10.1089/1094931041291295

Thomas, H. J., Connor, J. P., \& Scott, J. G. (2015). Integrating traditional bullying and cyberbullying: Challenges of definition and measurement in adolescents - a review. Educational Psychology Review, 27, 135-152. doi:10.1007/s10648-014-9261-7

Van den Bulck, J. (2004). Television viewing, computer game playing, and Internet use and selfreported time to bed and time out of bed in secondary-school children. Sleep, 27, 101-104.

Walrave, M., \& Heirman, W. (2011). Cyberbullying: Predicting victimisation and perpetration. Children \& Society, 25, 59-72. doi:10.1111/j.1099-0860.2009.00260.x

Zhao, X., Lynch Jr., J. G., \& Chen, Q. (2010). Reconsidering Baron and Kenny: Myths and truths about mediation analysis. Journal of Consumer Research, 37, 197-206. doi:10.1086/651257

Zych, I., Ortega-Ruiz, R., \& Del Rey, R. (2015). Systematic review of theoretical studies on bullying and cyberbullying: Facts, knowledge, prevention, and intervention. Aggression and Violent Behavior, 23, 1-21. doi:10.1016/j.avb.2015.10.001 


\section{Tables}

Table 1

Means, Correlations and Standard Deviations (on the Diagonal)

\begin{tabular}{|c|c|c|c|c|c|c|c|}
\hline \multicolumn{2}{|c|}{ Variable } & 1 & 2 & 3 & 4 & 5 & 6 \\
\hline 1 & SQ T1 & \multicolumn{6}{|l|}{0.811} \\
\hline 2 & Anger T2 & -.295 & 1.280 & & & & \\
\hline 3 & CBP T1 & -.232 & .166 & .317 & & & \\
\hline 4 & CBP T2 & -.195 & .229 & .444 & .368 & & \\
\hline 5 & FDMU T1 & -.226 & .109 & .361 & .246 & .779 & \\
\hline \multirow[t]{2}{*}{6} & FDMU T2 & -.174 & .130 & .237 & .306 & .642 & .762 \\
\hline & $M$ & 4.416 & 3.360 & 1.219 & 1.264 & 3.062 & 3.143 \\
\hline
\end{tabular}




\section{Figures}

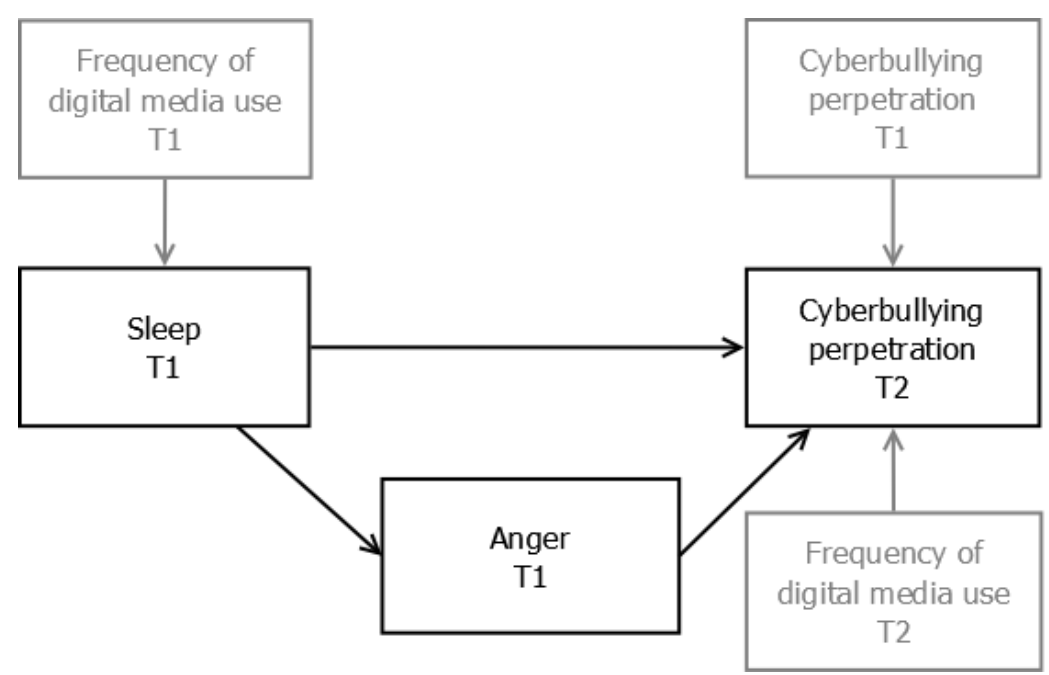

Figure 1. Conceptual model of the longitudinal association between sleep and cyberbullying with mediation via anger. Control variables are in gray.

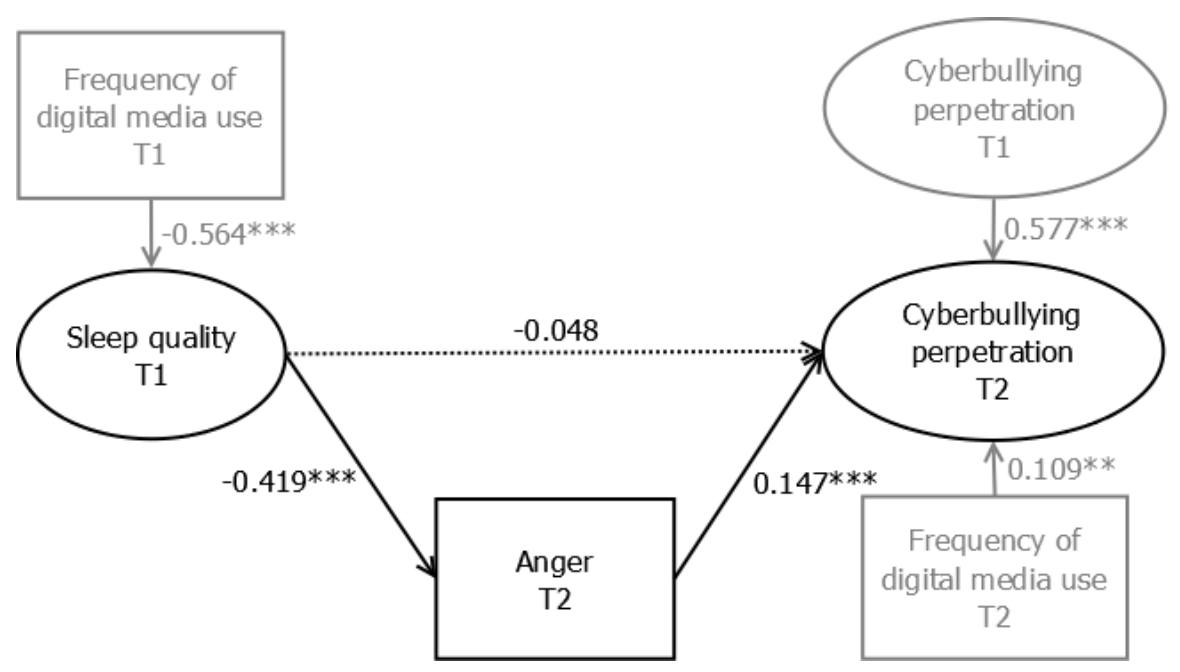

Figure 2. SEM model of the influence of sleep quality on later cyberbullying perpetration mediated via anger. Numbers indicate standardized parameter estimates. Control variables are in gray. $* * p<.01, * * * p<.001$. 